Çukurova Üniversitesi Mühendislik Mimarlık Fakültesi Dergisi, 35(2), ss. 537-550, Haziran 2020

Çukurova University Journal of the Faculty of Engineering and Architecture, 35(2), pp. 537-550, June 2020

\title{
Farklı Nemde Kurutma Havası Kullanılarak Kurutulan Yerfıstığının Kuruma Kinetiklerinin Deneysel Olarak Belirlenmesi
}

\author{
Kamil Neyfel ÇERÇ $\dot{I}^{* 1}$, Ertaç HÜRDOĞAN ${ }^{1}$ \\ ${ }^{1}$ Osmaniye Korkut Ata Üniversitesi, Mühendislik Fakültesi, Enerji Sistemleri Mühendisliği \\ Bölümü, Osmaniye
}

Geliş tarihi: $30.06 .2020 \quad$ Kabul tarihi: 30.07 .2020

$\ddot{\mathbf{O} z}$

Ürünlerin kurutularak saklanması eski çağlardan beri yaygın olarak kullanılan bir yöntemdir. Gıda kurutma işleminde temel amaç ürünün içerisinde bulunan suyun üründen uzaklaştırılmasıdır. Bu sayede ürün içerisindeki mikroorganizmaların gelişmesini durdurulacak ve ürünlerin raf ömrü uzatılacaktır. Bu çalışmada Osmaniye'de üretimi ve hasadı yapılan yerfıstığı ürününün kurutulması, kurutma havasının farklı mutlak nem değerleri için incelenmiştir. Yerfıstığının kuruma davranışı, tasarlanarak imal edilen deney düzeneği kullanılarak deneysel olarak belirlenmiştir. Çalışmada ayrıca deneysel olarak elde edilen alınabilir nem oranı değeri 22 farklı ince tabaka kurutma modeline fit edilmiştir. Çalışma sonucunda aynı sıcaklıkta kurutma havası için, kurutma havası nem değerinin düşmesi ile difüzyon katsayısının ve kuruma hızının arttığı gözlemlenmiş̧tir. Hii ve arkadaşları tarafından geliştirilen ince tabaka kuruma modeli, deneysel olarak elde edilen alınabilir nem oranı değerine en iyi yakınsayan model olarak belirlenmiştir.

Anahtar Kelimeler: Yer fistığı, Kurutma, Kuruma kinetikleri, Alınabilir nem oranı, Matematiksel model

\section{Experimental Determination of Drying Kinetics of Peanut Dried by using Drying Air at Different Humidity}

\begin{abstract}
Drying and storing of products is a widely used method since ancient times. The main purpose of the food drying process is to remove the water contained in the product from the product. In this way, the development of microorganisms in the product will be stopped and the shelf life of the products will be extended. In this study, the drying of the peanut product produced and harvested in Osmaniye was investigated for different absolute humidity values of the drying air. The drying behavior of peanuts was determined experimentally using the experimental setup designed and manufactured. In the study, the experimentally obtained moisture ratio value was fit to 22 different thin layer drying models. As a result of the study, it was observed that for the drying air at the same temperature, the diffusion coefficient and the drying rate increase with the decrease of the drying air humidity. The thin layer drying model developed by Hii et al. was determined as the model best converging to the experimentally obtained moisture ratio value.
\end{abstract}

Keywords: Peanut, Drying, Drying kinetics, Moisture ratio, Mathematical model

*Sorumlu Yazar: (Corresponding author): Kamil Neyfel ÇERÇí, kcerci@osmaniye.edu.tr 


\section{GíRiș}

Gıda endüstrisinde gıdalar, doğal formlarında iken (sebzeler, meyveler, tahillar, baharatlar, süt) veya işlendikten sonra (hazır kahve, çorba karışımları, peynir altı suyu) kurutulmaktadır. Gıdalar için kurutma, içerisindeki nemin değişik metotlarla alınarak, bozulmasına neden olan etkenlerin ortadan kaldırılması olarak başka bir ifade ile gıdadaki nemin uzaklaştırılması olarak tanımlanabilmektedir. Böylece ürün, bozulmalara karşı korunmakta ve raf ömrü uzamaktadır. Ayrıca kurutma sayesinde ürünlerin nakliyede kolaylık sağlaması için hacmi ve ağırlığı da azalmaktadır [1-4]. Birçok kurutma yöntemi arasında en sık kullanılanı, tabi kurutma olarak da adlandırılan günışı̆̆ında kurutmadır. Bu yöntemle kurutulan ürünlerin orijinal şeklini ve dokusunu (tekstür), taze iken sahip olduğu rengini ve vitamin içeriğini kaybetme eğilimi vardır. Ayrıca kurutma hızının hava şartlarına çok bağlı olması ve hava şartlarının değişiminin kontrol edilmesinin mümkün olmamas1, ürün kalitesinde bozulmalara sebep olmaktadır [5]. Kurutmanın gida kalitesi üzerine etkisi sadece besin değerleri üzerine değişimleri değil, aynı zamanda fiziksel, dokusal ve işlevsel değişimleri de kapsamaktadır. Tüketicilerin talepleri, ürünleri orijinal karakteristiklerinde tutma yönündedir. $\mathrm{Bu}$ talepler doğrultusunda çalışma maliyetlerini sınırlandırırken, bir yandan da hem işlemlerin olumsuz etkilerini minimize edecek çalışmaların geliştirilmesi hem de son ürünün kalitesinin korunması gerekmektedir. G1da kalitesi üzerine artan talepler kurutmada yenilikçi fikirlerin gelişmesine sebep olmuştur [6]. $\mathrm{Bu}$ yenilikçi fikirlerin temelinde kurutma hava şartlarının, kurutma kinetiğinde önemli rol oynadığı gerçeği bulunmaktadır. Kısa kurutma zamanlarında kurutulmuş kaliteli ürün eldesi ancak en iyi kurutma havası şartlarının elde edilmesi ile mümkün olmaktadır. Kurutma zamanı, kurutma havası sıcaklığının artması ile kısalmasına rağmen, özellikle sıcaklığa hassas kurutulan gida maddelerindeki renk ve tat değişimi, vitamin içeriğindeki değişim ve kurutulan üründeki yapısal bozukluklar (1sıl gerilmelerden kaynaklanan vb.) sıcaklık arttıkça daha fazla gerçekleşmektedir. Bu değişimler düşük sıcaklıkta kurutma yapılarak önlenebilmektedir. Düşük sıcaklıkta kurutma ise kurutma süresinin uzamasına neden olmaktadır. Düşük sıcaklıkta gıda kurutması uygulamalarında uzun kurutma zamanlarını kısaltmak için kurutulacak ürün üzerine mümkün olduğunca düşük nemde (kuru) hava göndermek gerekmektedir [6-8].

Yüksek sıcaklıkta kurutma işleminde zarar gören dolayısıyla düşük sıcaklıkta kurutulması gereken önemli gıda ürünlerinden biri yerfıstığı ürünüdür [9]. F1stıkta küflenme, hasattan itibaren başlamakta ve uzun süre devam eden soldurma ve kurutma aşamalarından dolayı ürün kalitesindeki düşüş ve ürün kayıplarıyla sonuçlanabilmek ayrıca ürettikleri mikotoksinler ile sağlık sorunlarına (mutajen, kanserojen, teratojen, tremorgen $\mathrm{vb}$ ) neden olabilmektedir $[10,11]$. Mikotoksinlerin en fazla üzerinde durulan grubu, toksik ve kanserojenik potansiyeli nedeniyle aflatoksinlerdir [12]. Yerfistığı ürününde hasat, hasat sonrası, kurutma ve depo öncesi dönemlerinde ortaya çıkan aflatoksin oluşumu ve seviyeleri yerfistığı ve ürünlerinin bütün dünyada mikotoksin; özellikle de aflatoksin kontiminasyonu açısından çok riskli bir gıda olduğu bilinmektedir. Arzu edilenin üzerinde nem içeren yerfıstıklarında, kısa sürede küflenme, aflatoksin oluşumu ve böceklenme başlayacağı ve bunun sonucunda, ürünün kalitesinde düşüş görülmektedir. Ayrıca farklı dönemlerde belirlenen aflatoksin bulaşıklığının, kurutma ve depo öncesi dönemde, hasat ve hasat sonrasina göre daha yüksek meydana gelmektedir. $\mathrm{Bu}$ sıkıntıların giderilmesi için, yerfıstığı alımı yapan büyük kuruluşların, merkezi alım yerlerinde, birer kurutma tesisini vakit geçirmeden kurmaları gerekmektedir [13]. Yerfistığı kurutma sıcaklığına çok duyarlıdır. Yapılan çalışmalarda, kurutma sıcaklığı $35{ }^{\circ} \mathrm{C}$ üzerine çıktığı zaman iç fistıkta çatlama ve tat değişimi meydana geldiği dolayısıyla dış hava sıcaklığı ne olursa olsun kurutma sıcaklığının üst limiti olarak $35^{\circ} \mathrm{C}$ olması gerektiği belirlenmiştir [9]. Diş hava sıcaklığının birkaç derece üzerine çıkılarak yapılan düşük sıcaklık kurutma işlemi yavaş gerçekleşen bir kurutma şeklidir. Amerika'da güneş altında 
kurutmanın neticesi olarak \%25'e varan ürün kayb1 olduğu rapor edilmiştir [14]. Bununla beraber güneş enerjisi ile kurutulan fistıklarda kurutma tepsilerinin üzerinde kalan fistıklarda iç fistıkta gözlenen çatlak oluşumunun tepsinin altında kalan fistıklardan $\% 25$ daha az olduğu ve kurutulan fistık kalitesinin düzgün bir dağılıma sahip olmadığı belirtilmiştir [15].

Gıda kurutmanın temel kimyası ve fiziği oldukça karmaşıktır. $\mathrm{Bu}$ nedenle uygulamada kurutucu, sadece nemi uzaklaştıran bir cihazdan çok daha karmaşıktır. Dolayısıyla kurutma sistemlerinde proses tasarımı, optimizasyon, enerji entegrasyonu ve kontrol için etkili modeller gereklidir [16]. İnce tabaka kurutma denklemleri kurutmanın matematiksel modellemesinde önemli araçlardır. $\mathrm{Bu}$ denklemler pratiktirler ve yeterince iyi sonuçlar verirler. İnce tabaka kurutma denklemlerini kullanmak için, kurutma hızı eğrilerinin bilinmesi gerekir. Bununla birlikte, katılardaki nem taşınımının daha iyi anlaşılmasını açıklığa kavuşturmaya yönelik kayda değer iş hacmi derinlemesine ele alınmamaktadır. Uygulamada, kurutma hızı eğrileri temel ilkelerden hesaplanmak yerine deneysel olarak ölçülmelidir [17]. İnce tabaka kurutma genellikle bir örnek parçacık veya dilim tabakası olarak kurutmak anlamına gelir [18]. İnce tabaka kurutma denklemlerinin karmaşık dağıtılmış modellerden farklı olarak daha az veri gerektirdiği için kullanımlarının kolay olduğu ve bu sebeple geniş uygulamalara sahip olduğu literatürde görülmektedir $[19,20]$. Literatürde ince tabaka kuruma davranışlarının incelendiği farklı birçok çalışma bulunmaktadır [21-32]. John ve arkadaşları [21], yaptıkları deneysel çalışmada ince tabaka kurutma modeli ile kabuklu ve iç fistığın kuruma davranışını mikrodalga yöntemi ile incelemişlerdir. Yazarlar mikrodalga gücünün kurutma hızına etkisini belirlemek için farklı hava debisi, sıcaklık ve bağıl nemde deneyler gerçekleştirmişlerdir. Çalışma sonunda mikrodalga yöntemi ile kuruma oranları geleneksel vagon tipi kurutucuya göre kabuklu fıstık için 10 ile 94 kat, iç fıstıkta ise 8 ile 32 kat artmıştır. Ayrıca çalışmada kullanılan ince tabaka kuruma modeli olan iki terimli üstel eşitliğin iyi uyum gösterdiği görülmüştür. Çerçi ve arkadaşları [24], güneş enerjisi destekli bir kurutucuda kabak dilimlerini kurutmuş ve kabak ürününün deneysel olarak elde edilen ANO değerlerini yirmi iki farklı ince tabaka kurutma modeline fit ederek en uygun modeli belirlemişlerdir. Çalışmada en iyi sonuç veren modellerin Kübik ve Modifiye Midilli-1 modelleri olduğu görülmüştür. Çalışma sonunda kabak ürünlerinin konvektif isı transfer, kütle transfer ve difüzyon katsayıları sırasıyla $5,18124 \mathrm{~W} / \mathrm{m}^{2}{ }^{\circ} \mathrm{C}$, $1,57129 \times 10^{-7} \mathrm{~m} / \mathrm{s}$ ve $2,335718 \times 10^{-9} \mathrm{~m}^{2} / \mathrm{s}$ olarak bulunmuştur. Doymaz [27], sıcak havalı bir kurutucuda üç farklı kurutma havası sıcaklığında (50, 60 ve $\left.70{ }^{\circ} \mathrm{C}\right)$ haşlanmış ve haşlanmamış Trabzon hurmasını kurutmuş, ürünlerin kurutma kinetiklerini hesaplamış ve altı farklı ince tabaka kuruma modeline göre incelemiştir. Çalışma sonunda, en kısa kurutma süresi haşlanmış Trabzon hurması ürünlerinde elde edilmiş ayrıca Midilli ve arkadaşları, Page ve Weibull modellerinin iyi sonuçlar verdiği gözlemlenmiștir. Dash ve ark [28], konvektif tepsi kurutucuda yıldız meyvesi dilimlerini kurutmuşlardır. Çalışmada yıldız meyvesinin kurutma kinetikleri hesaplanmış ve deneysel olarak ANO değerlerine en uygun olan ince tabaka kuruma modeli seçilmiştir. Deneylerde kurutma havası sicaklıkları olarak 50, 60, 70 ve $80^{\circ} \mathrm{C}$ seçilmiş ve en hızlı kuruma $80^{\circ} \mathrm{C}$ sıcaklıkta gerçekleşmiştir. Ayrıca on bir farklı ince tabaka kuruma modeli arasından en uygun modelin iki terimli üstel model $\left(\mathrm{R}^{2}=0,998248\right.$ ve $\chi 2=0,000193)$ olduğu saptanmıştır. Sahdev ve arkadaşları [32], güneş altında ve kapalı ortamda zorlanmış taşınımda yerfıstığı ürünlerinin ince tabaka kurutma davranışlarını incelemişlerdir. Yerfıstığı ürünleri yaş baza göre \%38'den \%8-10 değerleri aralığına kadar kurutulmuştur. Yerfıstığının kurutma davranışını belirlemek için dört farklı matematiksel model kullanılmıştır. Çalışma sonunda her iki kurutma yönteminde de en iyi modelin Henderson ve Pabis modeli olduğu, ikinci en iyi modelin ise Lewis modeli olduğu belirlenmiş ve bu iki modelin verilen koşullar altında yerfıstığının kuruma davranışını en iyi tanımlayan modeller olduğu sonucuna ulaşılmıştır. 
Yerfıstığı ürününü olabilecek en kısa süre içerisinde hem düşük sıcaklıkta hem de homojen bir şekilde kurutabilmek için kurutulacak ürün üzerine mümkün olduğunca düşük neme sahip kuru hava göndermek gerekmektedir. Böylece düşük sıcaklıkta düşük neme sahip kurutma havası ile üründen daha çok nem uzaklaştırılabilecektir. Aynı zamanda düşük nem de kurutma ile yukarıda belirtilen daha homojen ürün kurutma imkânı sağlanacaktır. $\mathrm{Bu}$ çalışmada yerfıstığı ürününün düşük sıcaklık $\left(35^{\circ} \mathrm{C}\right)$ ve farklı nemde kurutulması için bir kurutma sistemi tasarlanmış, imalatı yapılmış, deneyler gerçekleştirilmiş ve farklı nemde kurutulan yerfistığı ürününün kurutma kinetikleri belirlenmiştir. Çalışmada yerfıstığ ürünü için deneysel olarak elde edilen alınabilir nem oranı 22 farklı ince tabaka kuruma modeline fit edilmiş ve en uygun model belirlenmiştir.

\section{MATERYAL VE METOT}

\subsection{Deney Düzeneği ve Hesaplama Prosedürü}

Bu çalışma kapsamında, yerfıstığı ürününün düşük sıcaklıkta kurutulması için öncelikle bir deney düzeneği tasarlanarak kurulmuştur. Şekil 1'de kurutma deneyleri için tasarlanan deney düzeneğinin şematik görünümü verilmiştir. Deney düzeneği, soğutma ünitesi, 1sıtıcı ünitesi, soğuk buharlı nemlendirici, kurutma odası ve kontrollerin yapıldığı panelden oluşmaktadır. Deney düzeneğinin bulunduğu ortamdan (1 noktas1) soğutma ünitesi buharlaştırıcısının fanı vasıtasıyla alınan proses havası, buharlaştırıcı üzerinden geçerek soğuk ve kuru halde çıkmaktadır (2 noktası). Soğutulmuş ve nemi alınmış olan proses havası, daha sonra 1sitıcı ünitesine girmekte $(2 \rightarrow 3)$ ve istenilen (set edilen) kurutma havası sicaklığ elde edilmektedir. Sistemde istenilen kurutma havası nemi soğuk buharlı nemlendirici kullanılarak ayarlanmaktadır. Kurutma odasına belirli nem ve sıcaklık şartlarında giren hava, kurutulacak üründeki nemi üzerine almakta ve nemi artmış olarak kurutma odasını terk etmektedir
(4 noktas1). Deney düzeneğinde, literatürde yer alan benzer çalışmalar [30, 33] dikkate alınarak, homojen ve hızlı bir kuruma işlemi sağlanabilmesi için kurutma odası (test bölgesi) düşey olarak seçilmiştir. Sistemdeki tüm kontroller, kontrol paneli kullanılarak gerçekleştirilmektedir. Şekil 2'de Osmaniye Korkut Ata Üniversitesi, Osmaniye Meslek Yüksekokulu Laboratuvarlarında imal edilen kurutma sisteminin resmi verilmiştir. Modelleme için gerekli kurutma eğrilerinin belirlenebilmesi ve analizlerin gerçekleştirilebilmesi için deney düzeneği üzerinde sıcaklık, rölatif nem, hava hızı ve ağırlık ölçümleri gerçekleştirilmiştir. Deneyler boyunca ölçülen tüm parametreler bilgisayar destekli bir veri toplama sistemi kullanılarak $15 \mathrm{dk}$ aralıklarla kaydedilmiştir. Deneysel çalışmalarda ölçülen değerlerin doğruluğu ve deneyler sırasında farklı sebeplerden dolayı ortaya çıkabilecek hatalar, göz ardı edilmemesi gereken önemli faktörlerdir. $\mathrm{Bu}$ faktörlerin değerlendirilmesi için çalışmada belirsizlik analizi yapılmıştır. Deneysel çalışma içerisindeki belirsizlik analizi için Holman [34] tarafından önerilen yöntem kullanılmıştır. Çizelge 1'de, farklı parametrelerin ölçülmesi için kullanılan cihazlara ait bilgiler ve belirsizlik analiz sonuçları verilmiştir. Kurutma deneylerinde kullanılan yerfıstığı ürünü Osmaniye İli'nin Toprakkale İlçe'si Sarıüyük Köyü'ndeki bir tarladan toplanmıştır. Tazeliğini yitirmemesi ve daha doğru kurutma eğrilerinin elde edilmesinin sağlanması için yerfıstıkları kurutulmadan bir gün önce tarladan kurutulacak ürün miktarınca yaprakları ile birlikte toplanmış ve bu şekilde hava ile temasını kesmek (nem içeriğinin değişmemesi) için paketlenerek yaklaşık $4{ }^{\circ} \mathrm{C}$ sicaklıktaki buzdolabında bekletilmiştir. Kurutma işlemi öncesinde yapraklarından ve kabuklarından ayrıştırılan yerfıstığı ürünleri, kurutma tepsisine tek sira halinde dizilerek kurutma kabinine yerleştirilmiştir (Şekil 3). Deneyler, farklı mutlak nem ve düşük sıcaklık $\left(35^{\circ} \mathrm{C}\right)$ şartlarına sahip kurutma havası kullanılarak gerçekleştirilmiştir. 

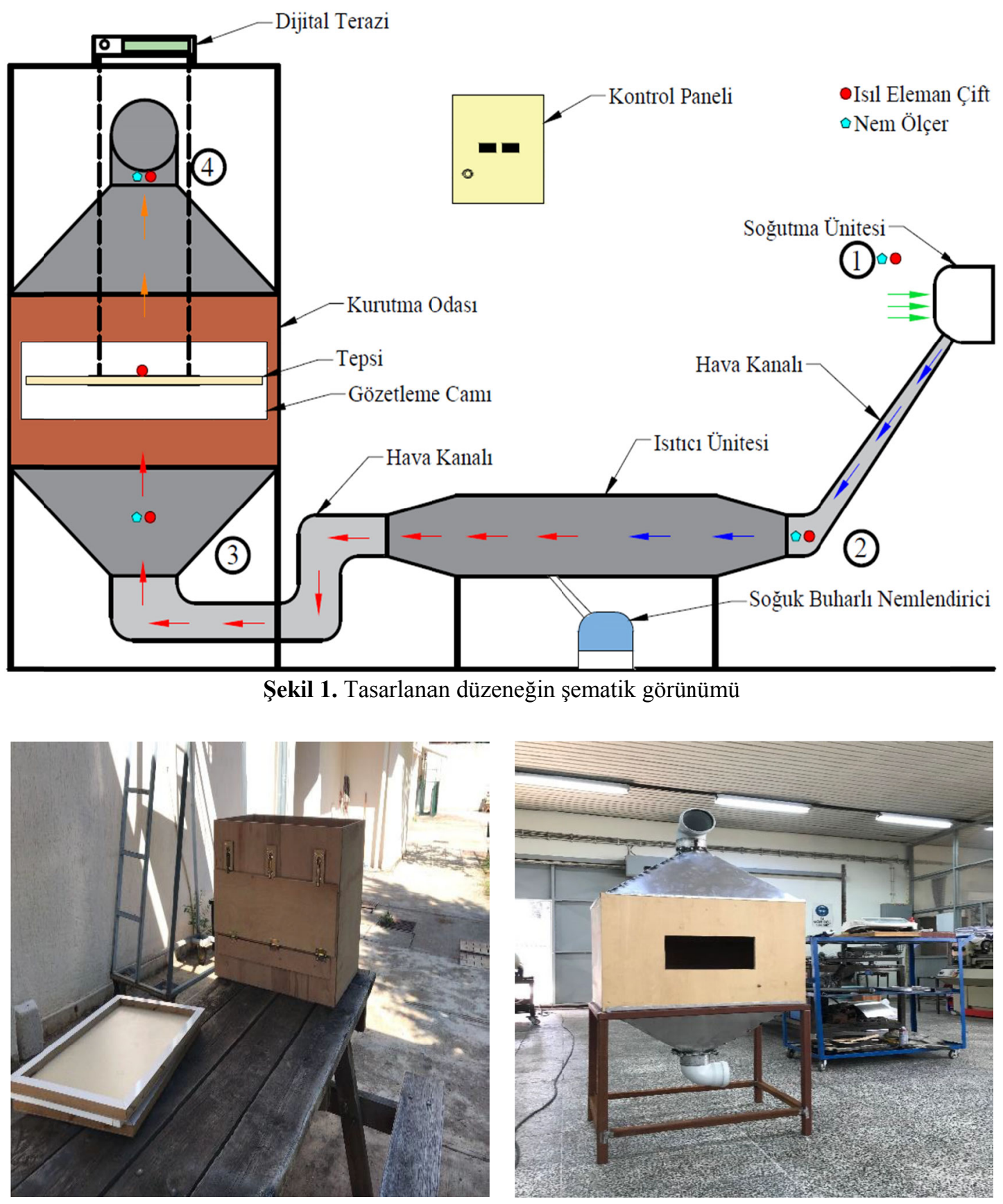
Farklı Nemde Kurutma Havası Kullanılarak Kurutulan Yerfistığının Kuruma Kinetiklerinin Deneysel Olarak Belirlenmesi
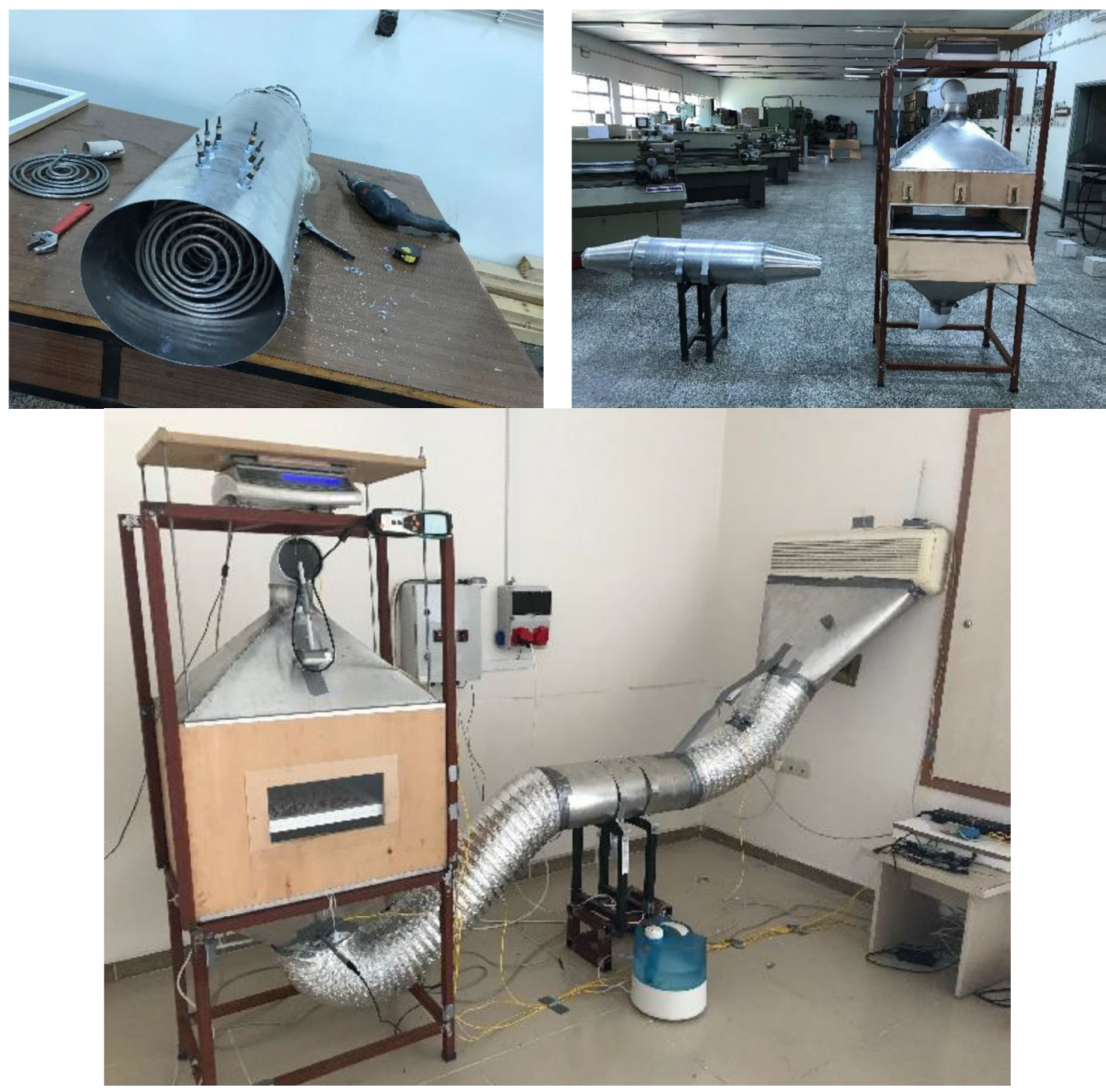

Şekil 2. Tasarlanıp kurulan kurutma sisteminin resmi ve imalat aşamalarının resimleri

Çizelge 1. Deneylerde kullanılan ölçüm cihazları

\begin{tabular}{|l|c|c|}
\hline Cihaz & Ölçüm Parametreleri & Hassasiyet \\
\hline TESTO 435 & Hava Hızı & $0,1 \mathrm{~m} / \mathrm{s}$ \\
\hline COLE PARMER Isıl Eleman Çifti & Sıcaklık & $0,1{ }^{\circ} \mathrm{C}$ \\
\hline EPLUSE Nem Ölçer & Rölatif nem & $2-3 \%$ \\
\hline IOTECH PD3001 Veri Kaydedici & Veri kayılt & $16 \mathrm{bit}$ \\
\hline DíKOMSAN Dijital Terazi & A ğırlık & $0,1 \mathrm{~g}$ \\
\hline Hesaplanan Parametre & & Belirsizlik (\%) \\
\hline Alınabilir Nem Oranı (ANO) & & 2,3 \\
\hline Kuruma Hızı (R) & & 2,6 \\
\hline
\end{tabular}



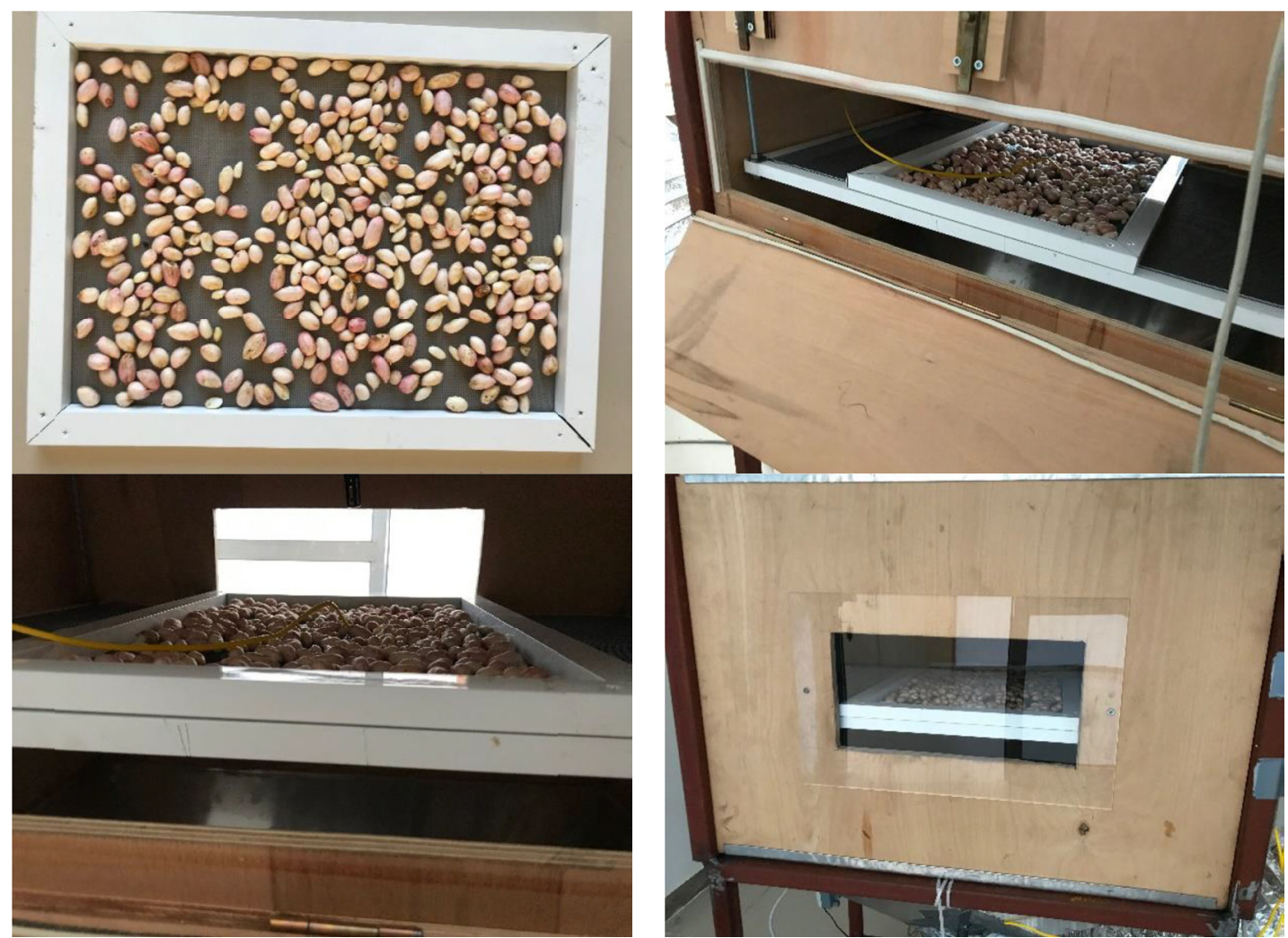

Şekil 3. Yerfıstığı ürünlerinin kurutma işlemi için hazırlanması ve kurutma işlemi

Çalışmada, yerfıstığının kuruma davranışı, kuruma zamanına bağlı olarak değişen nem içeriği ve kuruma hizı parametreleri ile karakterize edilmiştir. Kuru baza göre nem içeriği $\left(\mathrm{N}_{\mathrm{kb}}, \mathrm{kg}_{\mathrm{s}} / \mathrm{kg}_{\mathrm{km}}\right)$ ürün içerisindeki nem miktarının $\left(\mathrm{W}_{\mathrm{s}}, \mathrm{kg}_{\mathrm{s}}\right)$ ürünün kuru madde miktarına $\left(\mathrm{W}_{\mathrm{k}}, \mathrm{kg}_{\mathrm{km}}\right)$ oranı olarak Eşitlik 1 ile ifade edilmiştir [35]. Eşitlik 2'de ise yaş baza göre nem içeriği $\left(\mathrm{N}_{\mathrm{yb}}, \mathrm{kg}_{\mathrm{s}} / \mathrm{kg}\right)$ ifadesi ile kuru baza göre nem içeriğ $\mathrm{i}$ arasındaki bağıntı verilmiştir [36].

$\mathrm{N}_{\mathrm{kb}}=\frac{\mathrm{W}_{\mathrm{s}}}{\mathrm{W}_{\mathrm{k}}}$

$\mathrm{N}_{\mathrm{kb}}=\frac{\mathrm{W}_{\mathrm{s}}}{\mathrm{W}_{\mathrm{k}}}$

Kuruma hizı (R, $\left.\left(\mathrm{kg}_{\mathrm{s}} / \mathrm{kg}_{\mathrm{km}}\right) / \mathrm{dk}\right)$ parametresi Eşitlik 3 kullanılarak hesaplanmaktadır [35]:

$\mathrm{R}=\frac{\mathrm{N}_{\mathrm{kb}, \mathrm{t}}-\mathrm{N}_{\mathrm{kb}, \mathrm{t}+\Delta \mathrm{t}}}{\Delta \mathrm{t}}$
Burada, $\Delta \mathrm{t}$ zaman farkıdır (dk). Yerfistığı ürünlerinin alınabilir nem oranı (ANO) değerleri aşağıdaki Eşitlik 4 kullanılarak belirlenmiştir [30].

$\mathrm{ANO}=\frac{\mathrm{N}_{\mathrm{t}}-\mathrm{N}_{\mathrm{e}}}{\mathrm{N}_{0}-\mathrm{N}_{\mathrm{e}}}$

Burada, $\mathrm{N}_{\mathrm{t}}$ herhangi bir $\mathrm{t}$ anındaki nem oranı, $\mathrm{N}_{0}$ kurutmanın başlangıcındaki nem oranı, $\mathrm{N}_{\mathrm{e}}$ ise denge nem oranıdır. $\mathrm{N}_{\mathrm{e}}$ değeri gıda ürünlerinde $\mathrm{N}_{\mathrm{t}}$ ve $\mathrm{N}_{0}$ değerlerine kıyasla çok küçük kalmaktadır. $\mathrm{Bu}$ sebeple, ANO'nın hesaplanmasını kolaylaştırmak için Eşitlik 4 yerine $\mathrm{N}_{\mathrm{t}} / \mathrm{N}_{0}$ ifadesi kullanılmaktadır [23, 24].

\section{2. İnce Tabaka Kuruma Modelleri}

Çizelge 2'de, bu çalışma kapsamından deneysel olarak elde edilen ANO değerinin matematiksel olarak modellenebilmesinde ele alınan ve literatürde yer alan 22 farklı ince tabaka kurutma 
Farklı Nemde Kurutma Havası Kullanılarak Kurutulan Yerfistığının Kuruma Kinetiklerinin Deneysel Olarak Belirlenmesi

modelleri verilmiştir. Çizelgedeki eşitliklerde $a, b$, c, d, L, g, n, k, $\mathrm{k}_{0}$ ve $\mathrm{k}_{1}$ sabitleri, t zamanı (saniye) ifade etmektedir. En uygun modelin belirlenmesi için yapılan analizler, OriginPro programı kullanılarak gerçekleştirilmiştir.

ANO ve difüzyon katsayısı $\left(D_{\text {eff }}, \mathrm{m}^{2} / \mathrm{s}\right)$ değeri arasındaki ilişki aşağıdaki Eşitlik 5'te verilmiştir $[24,37]$.

$\mathrm{ANO}=\frac{8}{\pi^{2}} \exp \left\{-\pi^{2} \frac{\mathrm{D}_{\mathrm{eff}}^{\mathrm{t}}}{\mathrm{r}^{2}}\right\}$

Burada $r$ ürünün yarıçapı $(m)$ ve $t$ zamandır (s). ANO değerleri için kullanılan ince tabaka kurutma modellerinin en iyisinin seçilmesi için performans kriterleri olarak korelasyon sayıs $\left(\mathrm{R}^{2}\right)$ ve ki-kare $\left(\chi^{2}\right)$ değerlerine bakılmıştır. $\chi^{2}$ değerinin belirlenmesi için aşağıdaki Eşitlik 6'dan faydalanılmıştır.

$\chi^{2}=\frac{\sum_{\mathrm{i}=1}^{\mathrm{n}}\left(\mathrm{ANO}_{\mathrm{den}, \mathrm{i}}-\mathrm{ANO}_{\mathrm{tah}, \mathrm{i}}\right)^{2}}{\mathrm{~N}-\mathrm{n}}$

Burada, $\mathrm{ANO}_{\text {den,i }}$ deneysel gözlemler sonucu elde edilen alınabilir nem oranı değeri, $\mathrm{ANO}_{\text {pre, }}$ tahmin edilen alınabilir nem oranı değeri, $\mathrm{N}$ veri sayısı ve n sabit sayısıdır $[24,30]$.

Çizelge 2. ANO'nın modellenmesinde kullanılan ince tabaka kurutma modelleri

\begin{tabular}{|c|c|c|c|}
\hline Model No. & Model & Eşitlik & Kaynakça \\
\hline 1 & Lewis & $\mathrm{ANO}=\exp (\mathrm{k} \cdot \mathrm{t})$ & {$[38]$} \\
\hline 2 & Page & $\mathrm{ANO}=\exp \left(\mathrm{k} \cdot \mathrm{t}^{\mathrm{n}}\right)$ & [39] \\
\hline 3 & Modifiye Page & $\mathrm{ANO}=\exp (-\mathrm{k} \cdot \mathrm{t})^{\mathrm{n}}$ & [40] \\
\hline 4 & Henderson ve Pabis & $\mathrm{ANO}=\mathrm{a} \cdot \exp (-\mathrm{k} \cdot \mathrm{t})$ & [41] \\
\hline 5 & Hii ve arkadaşları & $\mathrm{ANO}=\mathrm{a} \cdot \exp \left(-\mathrm{k}_{0} \cdot \mathrm{t}^{\mathrm{n}}\right)+\mathrm{b} \cdot \exp \left(-\mathrm{k}_{1} \cdot \mathrm{t}^{\mathrm{n}}\right)$ & [42] \\
\hline 6 & Logaritmik & $\mathrm{ANO}=\mathrm{a} \cdot \exp (-\mathrm{k} \cdot \mathrm{t})+\mathrm{c}$ & [43] \\
\hline 7 & İki-terimli & $\mathrm{ANO}=\mathrm{a} \cdot \exp \left(-\mathrm{k}_{0} \cdot \mathrm{t}\right)+\mathrm{b} \cdot \exp \left(\mathrm{k}_{1} \cdot \mathrm{t}\right)$ & [44] \\
\hline 8 & Parabolik & $\mathrm{ANO}=\mathrm{a}+\mathrm{b} \cdot \mathrm{t}+\mathrm{c} \cdot \mathrm{t}^{2}$ & [45] \\
\hline 9 & Weibull & $\mathrm{ANO}=\exp \left(-(\mathrm{t} / \mathrm{b})^{\mathrm{a}}\right)$ & [46] \\
\hline 10 & Kübik & $\mathrm{ANO}=\mathrm{a}+\mathrm{b} \cdot \mathrm{t}+\mathrm{c} \cdot \mathrm{t}^{2}+\mathrm{d} \cdot \mathrm{t}^{3}$ & [47] \\
\hline 11 & Sigmoid & $\mathrm{ANO}=\mathrm{a}+\mathrm{b} /(1+\exp (\mathrm{k} \cdot(\mathrm{t}-\mathrm{c}))$ & [48] \\
\hline 12 & Vega-Lemus & $\mathrm{ANO}=(\mathrm{a}+\mathrm{b} \cdot \mathrm{t})^{2}$ & [49] \\
\hline 13 & Rasyonel & $\mathrm{ANO}=(\mathrm{a}+\mathrm{b} \cdot \mathrm{t}) /\left(1+\mathrm{c} \cdot \mathrm{t}+\mathrm{d} \cdot \mathrm{t}^{2}\right)$ & {$[50]$} \\
\hline 14 & Vega-Galvez I & $\mathrm{ANO}=\mathrm{n}+\mathrm{k} \cdot \sqrt{\mathrm{t}}$ & [51] \\
\hline 15 & Vega-Galvez II & $\mathrm{ANO}=\exp (\mathrm{n}+\mathrm{k} \cdot \mathrm{t})$ & {$[51]$} \\
\hline 16 & Modifiye Midilli II & $\mathrm{ANO}=\exp (-\mathrm{k} \cdot \mathrm{t})+\mathrm{b} \cdot \mathrm{t}$ & {$[4]$} \\
\hline 17 & Noomhorn ve Verma & $A N O=a \cdot \exp \left(-k_{0} \cdot t\right)+b \cdot \exp \left(-k_{1} \cdot t\right)+c$ & [52] \\
\hline 18 & Difüzyon Yaklaşımı & $A N O=a \cdot \exp (-k \cdot t)+(1-a) \cdot \exp (-k \cdot b \cdot t)$ & [53] \\
\hline 19 & Verma ve arkadaşları & $\mathrm{ANO}=\mathrm{a} \cdot \exp (-\mathrm{k} \cdot \mathrm{t})+(1-\mathrm{a}) \cdot \exp (-\mathrm{g} \cdot \mathrm{t})$ & [54] \\
\hline 20 & İki-terimli üstel & $A N O=a \cdot \exp (-k(\cdot t)+(1-a) \cdot \exp (-k \cdot a \cdot t)$ & {$[55]$} \\
\hline 21 & $\begin{array}{l}\text { Basitleştirilmiş Fick'in } \\
\text { difüzyon denklemi }\end{array}$ & $\mathrm{ANO}=\mathrm{a} \cdot \exp \left(-\mathrm{c} \cdot\left(\frac{\mathrm{t}}{\mathrm{L}^{2}}\right)\right)$ & {$[56]$} \\
\hline 22 & $\begin{array}{l}\text { Modified page equation } \\
\text { II }\end{array}$ & $\mathrm{ANO}=\exp \left(-\mathrm{k} \cdot\left(\frac{\mathrm{t}}{\mathrm{L}^{2}}\right)^{\mathrm{n}}\right)$ & {$[56]$} \\
\hline
\end{tabular}




\section{BULGULAR VE TARTIŞMA}

$\mathrm{Bu}$ çalışma kapsamında, yerfıstığının düşük sicaklık ve farklı nem değerlerine sahip kurutma havası şartlarına göre kuruma davranışları deneysel olarak incelenmiş ayrıca düşük nem değerleri için en uygun ince tabaka kurutma modeli seçilmiştir. $\mathrm{Bu}$ işlemler için yukarıda ayrıntıları verilen kurutma sistemi tasarlanmış ve kurulumu gerçekleştirilmiştir. Kurutulacak olan yerfistığı ürünleri her deney için yaklaşık olarak $325 \mathrm{~g}$ olarak ayarlanmıştır. Kurutma deneyleri kurutma havasının farklı mutlak nem şartlarında ve fistığın yüksek kurutma havası sıcaklıklarından zarar gördüğü göz önünde bulundurularak $35^{\circ} \mathrm{C}$ sıcaklıkta gerçekleştirilmiştir. Deneyler yaklaşık olarak 17 saat sürmüş ve kurutma süresi boyunca yerfıstığı ürününün kuruma davranışları gözlemlenmiştir. Şekil 4 'te $35^{\circ} \mathrm{C}$ sicaklık ve farklı mutlak nem değerlerinde kurutulan ürünlerin kuru baza ve yaş baza göre nem içeriklerinin deney süresince değişimleri verilmiştir. Şekillerdeki nem içeriklerinin değişimlerine bakıldığında, aynı süre içerisinde en büyük düşüş $35{ }^{\circ} \mathrm{C}-5,22 \mathrm{~g}_{\mathrm{s}} / \mathrm{kg}_{\mathrm{kh}}$ kurutma havası şartlarında gerçekleşmiştir. $35{ }^{\circ} \mathrm{C}-5,22 \quad \mathrm{~g}_{\mathrm{s}} / \mathrm{kg}_{\mathrm{kh}}$ kurutma havası şartlarında kurutma işlemi boyunca, üründe yaklaşık $0,78 \quad \mathrm{~kg}_{\mathrm{s}} / \mathrm{kg}_{\mathrm{km}} \quad\left(0,44 \quad \mathrm{~kg}_{\mathrm{s}} / \mathrm{kg}\right)$ nem içeriğinden $0,035 \mathrm{~kg}_{\mathrm{s}} / \mathrm{kg}_{\mathrm{km}}\left(0,033 \mathrm{~kg}_{\mathrm{s}} / \mathrm{kg}\right)$ nem içeriğine kadar nem düşüşü gözlemlenmiştir. $35^{\circ} \mathrm{C}-8,40 \quad \mathrm{~g}_{\mathrm{s}} / \mathrm{kg}_{\mathrm{kh}}$ kurutma havası şartlarında ise kurutma işlemi boyunca, üründe yaklaşık olarak $0,78 \mathrm{~kg}_{\mathrm{s}} / \mathrm{kg}_{\mathrm{km}}$ $\left(0,44 \quad \mathrm{~kg}_{\mathrm{s}} / \mathrm{kg}\right)$ nem içeriğinden $0,17 \quad \mathrm{~kg}_{\mathrm{s}} / \mathrm{kg}_{\mathrm{km}}$ $\left(0,14 \mathrm{~kg}_{\mathrm{s}} / \mathrm{kg}\right)$ nem içeriğine kadar nem düşüşü gözlemlenmiştir.

Şekil 5'te farklı kurutma havası şartları için ürünün kuruma hızı değerlerinin zamanla değişimi verilmiștir. Şekilden kuruma hızında en yüksek değerlere $35{ }^{\circ} \mathrm{C}-5,22 \mathrm{~g}_{\mathrm{s}} / \mathrm{kg}_{\mathrm{kh}}$ kurutma havas1 şartlarında ulaşıldığı gözlemlenmiştir. Kurutma işleminin 585. dakikasında üründeki nem içeriğinin iyice azalmasıyla birlikte $35{ }^{\circ} \mathrm{C}-5,22 \quad \mathrm{~g}_{\mathrm{s}} / \mathrm{kg}_{\mathrm{kh}}$ kurutma havası şartlarındaki kuruma hızı diğer şartlardaki kuruma hızı değerleri ile benzer aralıklarda değişim göstermiştir. Çizelge 3'de farklı kurutma havası şartları için difüzyon katsayısı ve kurutma süresince kuruma hızı değişim aralığı değerleri verilmiştir.
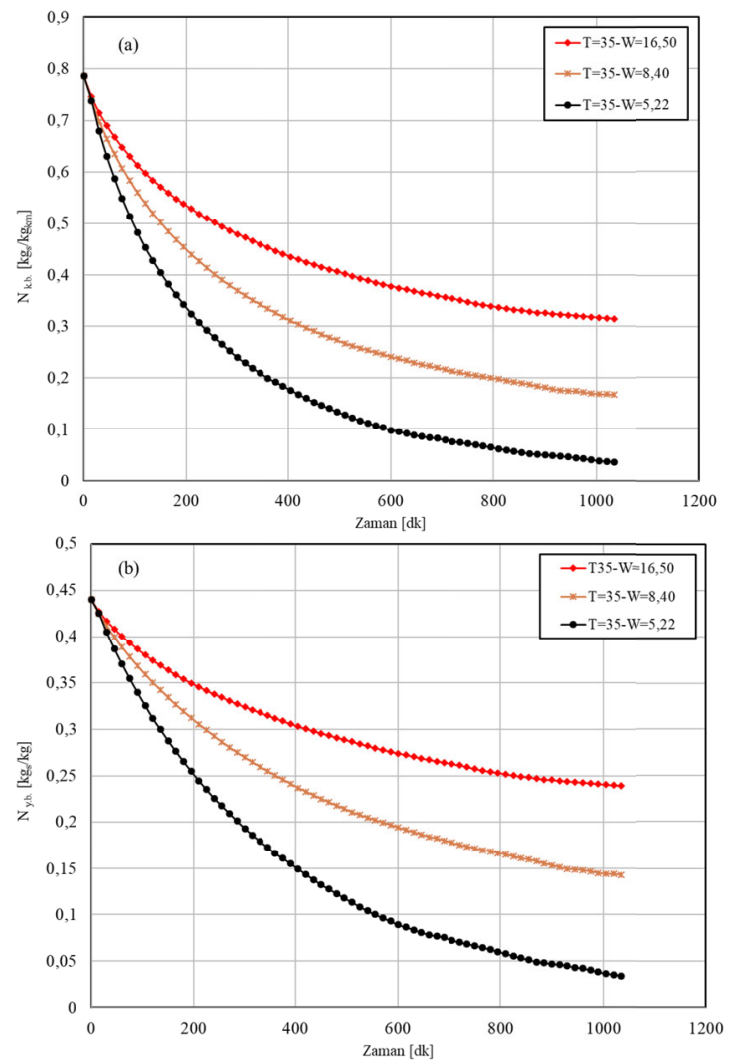

Şekil 4. Farklı kurutma havası şartlarına göre yerfıstığı ürününün sırasıyla kuru baza (a) ve yaş baza (b) göre nem içeriklerinin zamanla değişimi

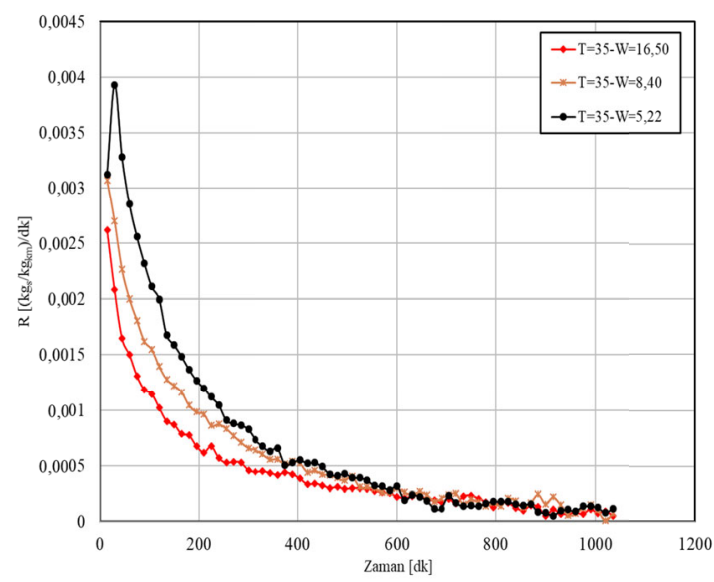

Şekil 5. Farklı kurutma havası şartlarına göre yerfıstığı ürününün kuruma hızının değişimi 
Farklı Nemde Kurutma Havası Kullanılarak Kurutulan Yerfistı̆̆ının Kuruma Kinetiklerinin Deneysel Olarak Belirlenmesi

Çizelge 3. Farklı kurutma havası şartlarında yerfıstığı ürününün difüzyon katsayısı $\left[\mathrm{m}^{2} / \mathrm{s}\right]$ ve kuruma hızı $\left[\left(\mathrm{kg}_{\mathrm{s}} / \mathrm{kg}_{\mathrm{km}}\right) / \mathrm{dk}\right]$ değişim aralı̆̆ 1

\begin{tabular}{|c|c|c|}
\hline Kurutma Havası Şartları & $\mathrm{D}_{\text {eff }}\left[\mathrm{m}^{2} / \mathrm{s}\right]$ & $\mathrm{R}\left[\left(\mathrm{kg}_{\mathrm{s}} / \mathrm{kg}_{\mathrm{km}}\right) / \mathrm{dk}\right]$ \\
\hline $\mathrm{T}=35^{\circ} \mathrm{C}, \mathrm{W}=5,22 \mathrm{~g}_{\mathrm{s}} / \mathrm{kg}_{\mathrm{kh}}$ & $1,3256 \mathrm{E}-10$ & $0,0039-5,398 \mathrm{E}-05$ \\
\hline $\mathrm{T}=35^{\circ} \mathrm{C}, \mathrm{W}=8,40 \mathrm{~g}_{\mathrm{s}} / \mathrm{kg}_{\mathrm{kh}}$ & $6,9897 \mathrm{E}-11$ & $0,0031-8,569 \mathrm{E}-06$ \\
\hline $\mathrm{T}=35^{\circ} \mathrm{C}, \mathrm{W}=16,50 \mathrm{~g}_{\mathrm{s}} / \mathrm{kg}_{\mathrm{kh}}$ & $3,8564 \mathrm{E}-11$ & $0,0026-5,274 \mathrm{E}-05$ \\
\hline
\end{tabular}

Çalışma kapsamında, $35^{\circ} \mathrm{C}$ sıcaklık ve düşük nem $\left(5,22\right.$ ve $\left.8,40 \mathrm{~g}_{\mathrm{s}} / \mathrm{kg}_{\mathrm{kh}}\right)$ değerlerine sahip kurutma havası şartlarında gerçekleştirilen deneylerde elde edilen alınabilir nem oranı (ANO) değerleri 22 farklı ince tabaka kurutma modeline uyarlanmış ve en uygun model seçilmiştir. Çizelge 4 ve 5 'de sirasiyla $35{ }^{\circ} \mathrm{C}-5,22 \mathrm{~g}_{\mathrm{s}} / \mathrm{kg}_{\mathrm{kh}}$ ve $35^{\circ} \mathrm{C}-8,40 \mathrm{~g}_{\mathrm{s}} / \mathrm{kg}_{\mathrm{kh}}$ kurutma havası için elde edilen sonuçlar verilmiştir. Her iki kurutma havası giriş şartlarında da en iyi yakınsama (yüksek $\mathrm{R}^{2}$-düşük $\chi^{2}$ ) Model 5 (Hii ve arkadaşları) [42] tarafından elde edilmiştir.

Çizelge 4. $35^{\circ} \mathrm{C}-5,22 \mathrm{~g}_{\mathrm{s}} / \mathrm{kg}_{\mathrm{kh}}$ kurutma havası için elde edilen sonuçlar

\begin{tabular}{|c|c|c|c|}
\hline Model No & Model Sabitleri & $\mathbf{R}^{2}$ & $\chi^{2}$ \\
\hline 1 & $\mathrm{k}=6,39859 \mathrm{E}-5$ & 0,98411 & $9,03367 \mathrm{E}-4$ \\
\hline 2 & $\mathrm{k}=3,38006 \mathrm{E}-4, \mathrm{n}=0,83127$ & 0,99894 & $6,10174 \mathrm{E}-5$ \\
\hline 3 & $\mathrm{k}=6,32401 \mathrm{E}-4, \mathrm{n}=0,10118$ & 0,98411 & $9,16460 \mathrm{E}-4$ \\
\hline 4 & $a=0,92635, k=5,88344 E-5$ & 0,99055 & $5,45302 \mathrm{E}-4$ \\
\hline 5 & $\begin{array}{l}a=1,07874, k_{0}=7,46501 E-4, n=0,75821, \\
b=-0,07874, k_{1}=2,05637\end{array}$ & 0,99988 & 6,94036E-6 \\
\hline 6 & $\mathrm{a}=0,91661, \mathrm{k}=7,16378 \mathrm{E}-5, \mathrm{c}=0,04971$ & 0,99781 & $1,27880 \mathrm{E}-4$ \\
\hline 7 & $\mathrm{a}=0,44298, \mathrm{k}_{0}=1,38005 \mathrm{E}-4, \mathrm{~b}=0,55931, \mathrm{k}_{1}=4,12075 \mathrm{E}-5$ & 0,99986 & $8,29731 \mathrm{E}-6$ \\
\hline 8 & $a=0,82901, b=-3,24059 E-5, c=3,34811 E-10$ & 0,96184 & 0,00223 \\
\hline 9 & $a=0,82705, b=14961,14857$ & 0,99895 & $6,03988 \mathrm{E}-5$ \\
\hline 10 & $a=0,9321, b=-5,27674 E-5, c=1,14857 \mathrm{E}-9, d=-8,61116 \mathrm{E}-15$ & 0,99392 & 3,61071E-4 \\
\hline 11 & $\begin{array}{l}a=0,04971, b=44066,28892, c=-131615,06987, \\
k=7,16418 E-5\end{array}$ & 0,99781 & $1,29819 \mathrm{E}-4$ \\
\hline 12 & $\mathrm{a}=0,91703, \mathrm{~b}=-1,80557 \mathrm{E}-5$ & 0,94327 & 0,00327 \\
\hline 13 & $a=1, b=-59140,42269, c=-49279,5997, d=-8,89552$ & 0,97112 & 0,00172 \\
\hline 14 & $\mathrm{n}=0,87606, \mathrm{k}=-0,00373$ & 0,92497 & 0,00433 \\
\hline 15 & $\mathrm{n}=-0,07677, \mathrm{k}=-5,88012 \mathrm{E}-5$ & 0,99055 & $5,45303 \mathrm{E}-4$ \\
\hline 16 & $\mathrm{k}=7,00514 \mathrm{E}-5, \mathrm{~b}=8,849 \mathrm{E}-7$ & 0,99504 & $2,85857 \mathrm{E}-4$ \\
\hline 17 & $\mathrm{a}=0,90665, \mathrm{~b}=0,04608, \mathrm{k}_{0}=7,01226 \mathrm{E}-5, \mathrm{k}_{1}=0,05, \mathrm{c}=0,04727$ & 0,99821 & $1,08143 \mathrm{E}-4$ \\
\hline 18 & $\mathrm{a}=0,44751, \mathrm{~b}=0,3021, \mathrm{k}=1,35574 \mathrm{E}-4$ & 0,99986 & $8,32531 \mathrm{E}-6$ \\
\hline 19 & $\mathrm{a}=45557,15108, \mathrm{k}=7,75089 \mathrm{E}-5, \mathrm{~g}=7,75092 \mathrm{E}-5$ & 0,98049 & 0,00114 \\
\hline 20 & $\mathrm{a}=0,2772, \mathrm{k}=1,76692 \mathrm{E}-4$ & 0,99901 & $5,69146 \mathrm{E}-5$ \\
\hline 21 & $\mathrm{a}=0,92622, \mathrm{c}=12,24624, \mathrm{~L}=458,82019$ & 0,99043 & $5,60047 \mathrm{E}-4$ \\
\hline 22 & $\mathrm{k}=0,63396, \mathrm{~L}=-92,85872, \mathrm{n}=0,8271$ & 0,99895 & $6,12872 \mathrm{E}-5$ \\
\hline
\end{tabular}


Çizelge 5. $35^{\circ} \mathrm{C}-8,40 \mathrm{~g}_{\mathrm{s}} / \mathrm{kg}_{\mathrm{kh}}$ kurutma havası için elde edilen sonuçlar

\begin{tabular}{|c|l|c|c|}
\hline $\begin{array}{c}\text { Model } \\
\text { No }\end{array}$ & Model Sabitleri & $\mathbf{R}^{\mathbf{2}}$ & $\chi^{\mathbf{2}}$ \\
\hline 1 & $\mathrm{k}=3,438 \mathrm{E}-5$ & 0,89945 & 0,00403 \\
\hline 2 & $\mathrm{k}=9,73928 \mathrm{E}-4, \mathrm{n}=0,67512$ & 0,99507 & $2,00135 \mathrm{E}-4$ \\
\hline 3 & $\mathrm{k}=7,78999 \mathrm{E}-6, \mathrm{n}=4,41433$ & 0,89945 & 0,00408 \\
\hline 4 & $\mathrm{a}=0,85752, \mathrm{k}=2,81386 \mathrm{E}-5$ & 0,95660 & 0,00176 \\
\hline 5 & $\mathbf{a}=\mathbf{0 , 6 5 9 4 5 ,} \mathbf{k}_{\mathbf{0}}=\mathbf{2 , 5 8 2 5 E}-\mathbf{4}, \mathbf{n}=\mathbf{0 , 8 6 6 1 6}, \mathbf{b}=\mathbf{0 , 3 4 2 1 7}, \mathbf{k}_{\mathbf{1}}=\mathbf{4 , 0 4 4 3 6 E - 5}$ & $\mathbf{0 , 9 9 9 9 7}$ & $\mathbf{1 , 2 7 8 3 2 E - 6}$ \\
\hline 6 & $\mathrm{a}=0,75449, \mathrm{k}=5,78599 \mathrm{E}-5, \mathrm{c}=0,204$ & 0,99761 & $9,86765 \mathrm{E}-5$ \\
\hline 7 & $\mathrm{a}=0,50701, \mathrm{k}_{0}=9,40668 \mathrm{E}-5, \mathrm{~b}=0,47744, \mathrm{k}_{1}=1,36904 \mathrm{E}-5$ & 0,99969 & $1,31308 \mathrm{E}-5$ \\
\hline 8 & $\mathrm{a}=0,87954, \mathrm{~b}=-2,54925 \mathrm{E}-5, \mathrm{c}=2,49361 \mathrm{E}-10$ & 0,97694 & $9,50613 \mathrm{E}-4$ \\
\hline 9 & $\mathrm{a}=0,67257, \mathrm{~b}=28882,89397$ & 0,99508 & $1,99846 \mathrm{E}-4$ \\
\hline 10 & $\mathrm{a}=0,947, \mathrm{~b}=-3.90153 \mathrm{E}-5, \mathrm{c}=7.97691 \mathrm{E}-10, \mathrm{~d}=-5.88653 \mathrm{E}-15$ & 0.99649 & $1.46708 \mathrm{E}-4$ \\
\hline 11 & $\mathrm{a}=0.20401, \mathrm{~b}=3914.51841, \mathrm{c}=-147818.15658, \mathrm{k}=5.78684 \mathrm{E}-5$ & 0.99761 & $1.00219 \mathrm{E}-4$ \\
\hline 12 & $\mathrm{a}=0.88715, \mathrm{~b}=-8.63933 \mathrm{E}-6$ & 0.90511 & 0.00385 \\
\hline 13 & $\mathrm{a}=1, \mathrm{~b}=4.03066 \mathrm{E} 45, \mathrm{c}=4.0739 \mathrm{E} 45, \mathrm{~d}=2.50036 \mathrm{E} 41$ & 0.99988 & $4.97418 \mathrm{E}-6$ \\
\hline 14 & $\mathrm{n}=0.94226, \mathrm{k}=-0.00321$ & 0,96079 & 0,00159 \\
\hline 15 & $\mathrm{n}=-0,15396, \mathrm{k}=-2,8122 \mathrm{E}-5$ & 0,95660 & 0,00176 \\
\hline 16 & $\mathrm{k}=4,88547 \mathrm{E}-5, \mathrm{~b}=3,14248 \mathrm{E}-6$ & 0,98873 & $4,57648 \mathrm{E}-4$ \\
\hline 17 & $\mathrm{a}=-78,58638, \mathrm{~b}=0,29552, \mathrm{k}_{0}=-1,21746 \mathrm{E}-7, \mathrm{k}_{1}=0,2113, \mathrm{c}=79,29085$ & 0,86834 & 0,00560 \\
\hline 18 & $\mathrm{a}=0,491, \mathrm{~b}=0,14219, \mathrm{k}=1,04181 \mathrm{E}-4$ & 0,99947 & $2,16855 \mathrm{E}-5$ \\
\hline 19 & $\mathrm{a}=0,83815, \mathrm{k}=2,72887 \mathrm{E}-5, \mathrm{~g}=0,668$ & 0,96496 & 0,00144 \\
\hline 20 & $\mathrm{a}=0,99836, \mathrm{k}=3,41975 \mathrm{E}-5$ & 0,89939 & 0,00409 \\
\hline 21 & $\mathrm{a}=0,85738, \mathrm{c}=5,43767, \mathrm{~L}=439,70319$ & 0,95660 & 0,00179 \\
\hline 22 & $\mathrm{k}=0,97624, \mathrm{~L}=166,93921, \mathrm{n}=0,67261$ & 0,99508 & $2,02828 \mathrm{E}-4$ \\
\hline
\end{tabular}

\section{SONUÇLAR}

$\mathrm{Bu}$ çalışmada, düşük sıcaklık $\left(35^{\circ} \mathrm{C}\right)$ ve farklı mutlak nem kurutma havası giriş şartlarında, yerfıstığı ürünü için kurutma deneyleri gerçekleştirilmiştir. Deneyler yaklaşık olarak 17 saat sürmüştür. $35{ }^{\circ} \mathrm{C}-5,22 \quad \mathrm{~g}_{\mathrm{s}} / \mathrm{kg}_{\mathrm{kh}}$ kurutma havası şartlarında kurutma işlemi boyunca, üründe yaklaşık $\quad 0,78 \quad \mathrm{~kg}_{\mathrm{s}} / \mathrm{kg}_{\mathrm{km}} \quad\left(0,44 \quad \mathrm{~kg}_{\mathrm{s}} / \mathrm{kg}\right) \quad$ nem içeriğinden $0,035 \quad \mathrm{~kg}_{\mathrm{s}} / \mathrm{kg}_{\mathrm{km}}\left(0,033 \quad \mathrm{~kg}_{\mathrm{s}} / \mathrm{kg}\right)$ nem içeriğine kadar nem düşüşü gözlemlenmiştir. $35^{\circ} \mathrm{C}-8,40 \mathrm{~g}_{\mathrm{s}} / \mathrm{kg}_{\mathrm{kh}}$ kurutma havası şartlarında ise kurutma işlemi boyunca, üründe yaklaşık olarak $0,78 \quad \mathrm{~kg}_{\mathrm{s}} / \mathrm{kg}_{\mathrm{km}} \quad\left(0,44 \quad \mathrm{~kg}_{\mathrm{s}} / \mathrm{kg}\right)$ nem içeriğinden $0,17 \mathrm{~kg}_{\mathrm{s}} / \mathrm{kg}_{\mathrm{km}}\left(0,14 \mathrm{~kg}_{\mathrm{s}} / \mathrm{kg}\right)$ nem içeriğine kadar nem düşüşü gözlemlenmiştir. Aynı sıcaklığa sahip kurutma havasının nem değeri düşürüldükçe, difüzyon katsayısı ve kuruma hızının arttığı tespit edilmiştir. $\mathrm{Bu}$ sebeple yüksek sıcaklıktan zarar gören yerfıstığg ürününde kuruma süresini azaltmak için, kurutma havasının mutlak nemini düşürmek gerektiği görülmüştür. Ayrıca çalışma kapsamında, $35^{\circ} \mathrm{C}$ sıcaklık ve düşük nem $(5,22$ ve $\left.8,40 \quad \mathrm{~g}_{\mathrm{s}} / \mathrm{kg}_{\mathrm{kh}}\right)$ değerlerine sahip kurutma havas1 şartlarında gerçekleştirilen deneylerden elde edilen alınabilir nem oranı (ANO) değerleri 22 farklı ince tabaka kurutma modeline uyarlanmış ve en uygun model seçilmiştir. Her iki kurutma havası giriş şartları için en iyi yakınsamanın, Hii ve arkadaşları [42] tarafindan önerilen matematiksel model ile sağlandığ1 görülmüştür.

\section{TEŞEKKÜR}

$\mathrm{Bu}$ çalışma Osmaniye Korkut Ata Üniversitesi Bilimsel Araştırma Projeleri Birimi (OKÜBAP) tarafından OKÜBAP-2018-PT3-015 numaralı proje kapsamında desteklenmiştir. Desteklerinden dolayı OKÜBAP'a teşekkür ederiz. Ayrıca deney düzeneğinin kurulumu ve deneylerin gerçekleştirilmesi aşamalarında katkıda bulunan Doğan Burak SAYDAM'a teşekkür ederiz. 


\section{KAYNAKLAR}

1. Ceylan, I., Aktas, M., 2008. Hazelnut Drying in a Dryer Assisted Heat Pump, Journal of the Faculty of Engineering and Architecture of Gazi University, 23(1), 215-222.

2. Keey, R., 1972. Introduction. In: Drying Principles and Practice, pp. 1-18, Keey, R.B. Eds., Pergamon Press, Oxford.

3. Mujumdar, A., 1997. Drying Fumdamentals. In: Industrial Drying of Foods, pp. 7-30, Baker, C.G.J. Eds., Chapman \& Hall, London.

4. Erbay, Z., Icier, F., 2010. A Review of Thin Layer Drying of Foods: Theory, Modeling and Experimental Results, Critical Reviews in Food Science and Nutrition, 50(5), 441-464.

5. Nagaya, K., Li, Y., Jin, Z., Fukumuro, M., Ando, Y., Akaishi, A., 2006. Low-temperature Desiccant-based Food Drying System with Airflow and Temperature Control, Journal of Food Engineering, 75(1), 71-77.

6. Karam, M.C., Petit, J., Zimmer, D., Baudelaire Djantou, E., Scher, J., 2016. Effects of Drying and Grinding in Production of Fruit and Vegetable Powders: A Review, Journal of Food Engineering, 188, 32-49.

7. Misha, S., Mat, S., Ruslan, M.H., Sopian, K., 2012. Review of Solid/liquid Desiccant in the Drying Applications and its Regeneration Methods, Renewable and Sustainable Energy Reviews, 16(7), 4686-4707.

8. Kaya, A., Aydin, O., Dincer, I., 2008. Experimental and Numerical Investigation of Heat and Mass Transfer During Drying of Hayward Kiwi Fruits (Actinidia Deliciosa Planch), Journal of Food Engineering, 88(3), 323-330.

9. Butts, C.L., Williams, E.J., Sanders, T.H., 2002. Algorithms for Automated Temperature Controls to Cure Peanuts, Postharvest Biology and Technology, 24(3), 309-316.

10. Gürses, M., Eroğan, A., Sert, S., 2003. Erzurum Piyasasında Satılan Yerfistığı, Antepfistığ 1 ve Bademlerin Aflatoksin Yönünden İncelenmesi, Gıda, 28(6), 607-610.

11. Gürsoy, N., Biçici, M., 2006. Çukurova Bölgesinde Yetiştirilen Yerfıstıklarında Hasat,
Kurutma ve Depolama Kademelerinde Aflatoksin Oluşumu, Gıda, 31(4), 209-215.

12. Kabak, B., 2007. Bazı Mikotoksinlerin Detoksifikasyonunda Lactobacillus ve Bifidobacterium Suşlarının Kullanımı, Doktora Tezi, 164 s., Fen Bilimleri Enstitüsü, Çukurova Üniversitesi.

13. Lavkor, I., Biçici, M., 2015. Aflatoxin Occurrence in Peanuts Grown in Osmaniye at Harvest, Post-harvest, Drying and Pre-storage Periods, Tarım Bilimleri Dergisi, 21(3), 394-405.

14. Hoque A.K.M., 1993. Application of Liquid Desiccant Drying System in Agricultural Products, Graduate Faculty of Texas Tech University, Mechanical Engineering, Master of Science in Mechanical Engineering, Texas Tech University, 167p, Austin.

15. Troeger, J., Butler, J., 1977. Solar Drying of Peanuts in Georgia, in Solar Drying of Peanuts. Solar Crop Drying Conference Proceedings, 32-43.

16. Marinos-Kouris, D., Maroulis, Z., 1995. Transport Properties in the Drying of Solids. In:Handbook of Industrial Drying. pp.113-160 (Mujumdar, A.S. Eds., 2 ${ }^{\text {nd }}$ Edition), Marcel Dekker Inc., New York.

17. Baker, C.G., 1997. Preface. In: Industrial Drying of Foods, Baker, C.G.,Chapman \& Hall, London.

18. Kavak, Akpinar, E., Bicer, Y., Cetinkaya, F., 2006. Modelling of Thin Layer Drying of Parsley Leaves in a Convective Dryer and Under Open Sun, Journal of Food Engineering, 75(3), 308-315.

19. Madamba, P.S., Driscoll, R.H., Buckle, K.A., 1996. The Thin-layer Drying Characteristics of Garlic Slices, Journal of Food Engineering, 29(1), 75-97.

20. Ozdemir, M., Devres, Y.O., 2000. The Thin Layer Drying Characteristics of Hazelnuts During Roasting, Food Science and Technology Research, 42, 225-233.

21. St. John, C., Otten, L., 1989. Thin-layer Microwave Drying of Peanuts, Canadian Agricultural Engineering, 31(2), 265-270.

22. Sacilik, K., Keskin, R., Elicin, A.K., 2006. Mathematical Modelling of Solar Tunnel Drying of Thin Layer Organic Tomato, Journal 
of Food Engineering, 73 (3), 231-238.

23. Süfer, Ö., Sezer, S., Demir, H., 2017. Thin Layer Mathematical Modeling of Convective, Vacuum and Microwave Drying of Intact and Brined Onion Slices, Journal of Food Processing and Preservation, 41(6).

24. Çerçi, K.N., Sufer, Ö., Söyler, M., Hürdoğan, E., Özalp, C., 2018. Thin Layer Drying of Zucchini in Solar Dryer Located in Osmaniye Region, Tehnički Glasnik, 12(2), 79-85.

25. Akhondi, E., Kazemi, A., Maghsoodi, V., 2011. Determination of a Suitable Thin Layer Drying Curve Model for Saffron (Crocus Sativus L) Stigmas in an Infrared Dryer, Scientia Iranica, 18(6), 1397-1401.

26. Ponkham, K., Meeso, N., Soponronnarit, S., Siriamornpun, S., 2012. Modeling of Combined Far-infrared Radiation and Air Drying of a Ring Shaped-pineapple with/without Shrinkage, Food and Bioproducts Processing, 90(2), 155-164.

27. Doymaz, I., 2012. Evaluation of Some Thinlayer Drying Models of Persimmon Slices (Diospyros Kaki L.), Energy Conversion and Management, 56, 199-205.

28. Dash, K.K., Gope, S., Sethi, A., Doloi, M., 2013. Star Fruit Slices, International Journal of Agriculture and Food Science Technology., 4(7), 679-686.

29. Darvishi, H., Asl, A.R., Asghari, A., Azadbakht, M., Najafi, G., Khodaei, J., 2014. Study of the Drying Kinetics of Pepper, Journal of the Saudi Society of Agricultural Sciences, 13(2), 130-138.

30. Akpinar, E.K., Toraman, S., 2016. Determination of Drying Kinetics and Convective Heat Transfer Coefficients of Ginger Slices, Heat and Mass Transfer/Waerme- und Stoffuebertragung, 52(10), 2271-2281.

31. Darıcı, S., Şen, S., 2015. Experimental Investigation of Convective Drying Kinetics of Kiwi Under Different Conditions, Heat and Mass Transfer/Waerme- und Stoffuebertragung, 51 (8), 1167-1176.

32. Sahdev, R.K., Kumar, M., Dhingra, A.K., 2017. Development of Empirical Expression for Thin Layer Groundnut Drying Under Open Sun and Forced Convection Modes,
Agricultural Engineering International: CIGR Journal, 19(4), 152-158.

33. Kaya, A., 2008. Kurutmada Is1 ve Kütle Transferinin Teorik ve Deneysel Olarak İncelenmesi, Karadeniz Teknik Üniversitesi.

34. Holman, J., 2001. Experimental methods for engineers $\left(8^{\text {th }}\right.$ ed.), McGraw-Hill, ABD.

35. Akpınar, E., Biçer, Y., 2003. Investigation of Drying Behaviour of Pumpkin in a Cyclone, G.Ü. Fen Bilimleri Dergisi, 16(1), 159-169.

36. Hanif, S., Sultan, M., Miyazaki, T., Koyama, S., 2019. Investigation of Energy-efficient Solid Desiccant System for the Drying of Wheat Grains, International Journal of Agricultural and Biological Engineering, 12(1), 221-228.

37. Mota, C.L., Luciano, C., Dias, A., Barroca, M. J., Guiné, R.P.F., 2010. Convective Drying of Onion: Kinetics and Nutritional Evaluation, Food and Bioproducts Processing, 88(2-3), 115-123.

38. Bruce, D.M., 1985. Exposed-layer Barley Drying: Three Models Fitted to New Data Up to $150{ }^{\circ} \mathrm{C}$, Journal of Agricultural Engineering Research, 32(4), 337-348.

39. Page, G., 1949. Factors Influencing the Maximum Rates of Air Drying Shelled Corn in Thin Layers, Purdue Üniversitesi, Amerika.

40. White, G.M., Ross, I.J., Poneleit, C.G., 1981. Fully-Exposed Drying of Popcorn, Transactions of the American Society of Agricultural Engineers, 24(2), 466-468.

41. Henderson, S., Pabis, S., 1961. Grain Drying Theory I: Temperature Effect on Drying Coefficient, Journal of Agricultural Engineering Research, 6, 169-174.

42. Hii, C.L., Law, C.L., Cloke, M., 2009. Modeling Using a New Thin Layer Drying Model and Product Quality of Cocoa, Journal of Food Engineering, 90(2), 191-198.

43. Togrul, I.T., Pehlivan, D., 2002. Mathematical Modelling of Solar Drying of Apricots in Thin Layers, Journal of Food Engineering, 55(3), 209-216.

44. Henderson, S.M., 1974. Progress in Developing the Thin Layer Drying Equation., Transactions of the American Society of Agricultural Engineers, 17(6), 1-3.

45. Sharma, G.P., Prasad, S., 2004. Effective 
Moisture Diffusivity of Garlic Cloves Undergoing Microwave-convective Drying, Journal of Food Engineering, 65(4), 609-617.

46. Corzo, O., Bracho, N., Pereira, A., Vásquez, A., 2008. Weibull Distribution for Modeling Air Drying of Coroba Slices, LWT-Food Science and Technology, 41(10), 2023-2028.

47. Dalvand, M., Mohtasebi, S., Rafiee, S., 2012. Determining the Influence of Drying Conditions on EHD Drying Process, Journal of Agricultural and Biological Science, 7, 396-401.

48. Figiel, A., 2009. Drying Kinetics and Quality of Vacuum-microwave Dehydrated Garlic Cloves and Slices, Journal of Food Engineering, 94(1), 98-104.

49. Vega-Gálvez, A., Scala, K.D., Rodriguez, K., Lemus-Mondaca, R., Miranda, M., Lopez, J., Perez-Won, M., 2009. Effect of Air-drying Temperature on Physico-chemical Properties, Antioxidant Capacity, Colour and Total Phenolic Content of Red Pepper (Capsicum Annuum, L. var. Hungarian), Food Chemistry, 117(4), 647-653.

50. Haghi, A., Angiz, F., 2007. Heat and Mass Transfer in Thermal Drying of Wool: A Theoretical Approach, in Proceedings of the $5^{\text {th }}$ Asia-Pasific Drying Conference, 443-448.

51. Lemus-Mondaca, R., Miranda, M., Andres Grau, A., Briones, V., Villalobos, R., VegaGálvez, A., 2009. Effect of Osmotic Pretreatment on Hot Air Drying Kinetics and Quality of Chilean Papaya (Carica Pubescens), Drying Technology, 27(10), 1105-1115.

52. Noomhorn, A., Verma, L., 1986. Generalized Single-layer Rice Drying Models, Transactions of the ASAE, 29, 587-591.

53. Yaldiz, O., Ertekin, C., 2001. Thin Layer Solar Drying of Some Vegetables, Drying Technology, 19(3-4), 583-597.

54. Verma, L., Bucklin, R., Endan, J., Wratten F.T, 1985. Effects of Drying Air Parameters on Rice Drying Models, Transaction of the ASAE, 28, 296-301.

55. Sharaf-Eldeen, Y., Blaisdell, J., Hamdy, M., 1980. A Model for Ear Corn Drying, Transaction of the ASAE, 23(5), 1261-1271.

56. Diamante, L., Munro, P., 1991. Mathematical Modelling of Hot Air Drying of Sweet Potato
Slices, International Journal of Food Science and Technology, 26, 99-109. 